\title{
ANALYSIS OF PRODUCTION - INVENTORY DECISIONS IN A DECENTRALIZED SUPPLY CHAIN
}

\author{
Saeed Alaei, Masoud Behravesh, Nayere Karegar*
}

\begin{abstract}
:
Many contracts, such as buy-back policy, cost- and revenue- sharing policies, are widely applied in the literature for supply chain coordination problem. However, the additional gain from coordination may not necessarily cover the extra administrative costs incurred by applying these contracts. In this paper, a production inventory problem is considered in a two-level supply chain. The problem is formulated as a Stackelberg game. Then, the retail fixed mark-up (RFM) policy is examined in order to investigate its performance on supply chain. We apply this policy because of its lower administrative costs compared to other policies. We found that RFM policy is not capable of coordinating the channel; however, it leads to considerable improvements over the channel. For example, it is shown that it improves each member's profit and leads to Pareto improvement over Stackelberg policy. Besides, its average efficiency is about $96 \%$ of that of integrated policy approach.
\end{abstract}

Keywords: decentralized decision making, retail fixed mark-up (RFM), pricing decisions, supply chain coordination.

JEL Classification: C44, R32, P11

\section{Introduction}

Essentially, a supply chain is composed of independent members, each with its own objectives and individual costs. It is important how the members behave to manage their inventory. If they care only about overall system performance, they should choose policies to maximize total profit of supply chain, i.e. the integrated policy. This approach is appealing, but it has an important flaw. Each member may have his own objectives. So, when each firm is interested in maximizing its own profit independently, it chooses the strategies, in which the overall system performance could not necessarily be optimized, i.e. the decentralized policy. Therefore, a coordination mechanism is needed to improve the whole channel's performance. Note that the channel will be coordinated under one contract if i) none of the members' profit is worse compared with the decentralized policy; and, ii) channel's profit reaches its maximum as in integrated policy.

* Saeed Alaei, Department of Industrial Engineering, K. N. Toosi University of Technology, Tehran, Iran.; Masoud Behravesh and Nayere Karegar, Young Researchers and Elite Club, Marand Branch, Islamic Azad University, Marand, Iran (behrawesh@yahoo.com). 
There is extensive research in the literature on the channel coordination problem by means of designing efficient contracts, such as buyback contract, cost sharing, revenue sharing contracts and etc. Each of them might have some limitations; otherwise they would be applied in every industry. The supply chain incurs some extra administrative costs by applying these contracts. For example the monitoring costs are: retailer's actual sale in a buy-back contract, retailer's actual cost (revenue) in a cost (revenue) sharing contracts.

The additional gain from coordination may not necessarily cover these costs. The main contribution of the paper is applying a simple contract with near-optimal channel efficiency and lower administrative costs. Therefore, in our study, we apply RFM policy which is discussed in Liu et al. (2006). In RFM policy, only the retail price must be monitored. So, the administrative costs associated to this type of contract are lower than those of other contracts such as buyback policy, cost- and revenue- sharing contracts. We found that RFM policy is not capable of coordinating the channel; however, it leads to considerable improvements over the channel.

For example, it is shown that it improves each member's profit and leads to Pareto improvement over Stackelberg policy. Besides, its average efficiency is about $96 \%$ of that of integrated policy.

We consider a supply chain with one manufacturer and a single retailer in our production inventory system. An outside supplier supplies raw material to the manufacturer with zero lead time, and the manufacturer produces a product, and supplies it to a retailer who in turn supplies it to the consumers. Furthermore, assume that the retailer faces deterministic price-dependent demand. The retailer uses EOQ inventory policy for controlling his costs. The manufacturer operates on a make-to-order basis and uses a lot-for-lot policy, and he begins to produce a batch of $Q$, as soon as he receives an order and delivers it to the retailer after the lead time $(l)$. The research conducted in this paper presents a model of (1) integrated policy, in which the goal is to maximize the whole system profit, and (2) to evaluate decentralized-Stackelberg policy, in which individual firms in the supply chain have their own objectives and decisions to optimize.

In the Stackelberg approach, two firms play a game to achieve Stackelberg equilibrium. This equilibrium is a pair of policies in which each firm maximizes its own profit assuming the other player chooses his equilibrium policy. Thus, each firm makes an optimal decision given the behaviour of the other firm, and therefore, none of them has an incentive to deviate unilaterally from the equilibrium, and, (3) decentralized-retail fixed mark-up (RFM). In this policy, the manufacturer sets the wholesale price first, that is equivalent to setting the retail price. After that the retailer chooses his order size.

The paper tries to answer the following questions: how a contract can be offered so that each member will be in a win-win situation? And, is RFM policy capable of coordinating the channel? If not, how much is its efficiency? The first question says 
that the contract should be designed in a way that both members have incentives to approve it. When the manufacturer leads the channel, he has an opportunity to gain advantages of the retailer's information, such as profit function, demand and inventory information. By properly designing of RFM policy, this policy will be desirable for each member; therefore, both members will move from Stag policy to RFM policy. The second question investigates, whether the channel coordination will be achieved under RFM policy or not. We do not claim that RFM is capable of coordinating the channel. On the contrary, we show that RFM does not coordinate the channel in our study.

This paper is organized as follows. The next section reviews the related literature. Section 3 describes the notations, and the two firms' objective functions. Then we develop the integrated, Stackelberg, and retail fixed markup policies for the problem in Section 4 . We present a numerical study and the corresponding sensitivity analysis for some parameters with the purpose of evaluating the influence of these parameters on profits, the two firms' decision and evaluating Pareto-improving region in Section 5. Finally, Section 6 summarizes the results and covers the concluding remarks.

\section{Literature Review}

In the recent years, many papers have been published in the field of multi-echelon inventory management. Our study is related, at least in spirit, to supply chain coordination. In this section we review some papers that address Stackelberg game, retail fixed markup policy, and coordination mechanisms.

In the production inventory systems, Eliashberg and Steinberg (1987) consider production activities such as product delivery and inventory policy, and their relation to marketing strategies such as pricing policies. They investigate the problem as a Stackelberg game. Some other authors study this problem for a two-echelon supply chain, and apply the deterministic price-dependent demand curve, either linear or Iso-elastic. Parlar and Wang (1994) investigate discounting decisions for a supplier with a group of homogeneous buyers. They use Stackelberg game and show that both the seller and the buyer can gain considerably from quantity discount. Liou et al. (2006) study multi-period inventory models, in which the economic order quantity is integrated with the economic production quantity (EOQ-EPQ). They investigate the problem under the Stackelberg game approach to obtain the optimal policies. Furthermore, there are some other papers that applied Stackelberg game to analyse multi-echelon inventory systems.

In many industries fixed mark-ups are used such, as gasoline dealers, grocers, and electronics industry. In addition, RFM is also studied in marketing environment. Ha proposes three coordination mechanisms under a price-dependent demand. In the first, the order quantity set by the manufacturer; the second is a linear pricing policy; and, the third is based on RFM policy. Also, Li and Atkins (2002) consider this policy 
for marketing and operation sections in a single firm (Liu et al., 2006). Consider the RFM policy and examine the newsvendor problem with a single manufacturer in a decentralized channel under a price-dependent demand. They also formulate the problem under a price-only contract, and, show that RFM leads to Pareto improvement over the price-only contract. Our model is different from Liu et al.'s. Their model is based on newsvendor problem, but our model is absolutely different.

We assume inventory related costs for retailer and manufacturer, time-dependent production cost and technology development costs.

There have been extensive researches in the field of supply chain coordination. Qin et al. (2007) consider a price discount policy in a system with price-sensitive demand. Cachon and Zipkin (1999) investigate some incentive contracts to coordinating the two-echelon supply chain. Viswanathan and Piplani (2001) study a coordination problem, in which the vendor persuades the buyers to replenish only at the specific time periods by price discount policy. Cachon and Lariviere (2005) study some coordination mechanisms such as price-discount, buy-back, quantity discounts, franchise fee, quantity-flexibility, revenue sharing, and sales-rebate contracts. Some recently published papers consider coordination problem with marketing-pricing decisions in a two echelon supply chain. Yue et al. (2006) investigate the price discount scheme. Karray and Martín-Herrán (2009) study an advertising and pricing competition between national and store brands. He et al. consider a stochastic Stackelberg differential game; Szmerekovsky and Zhang (2009) formulate this problem as a Stackelberg game, in which the manufacturer is the leader. Xie and Wei (2009) consider cooperative and Stackelberg game. Xie and Neyret (2009) and SeyedEsfahani et al. (2011) investigate this problem by applying four game-theoretic models including cooperative, Nash, Stackelberg-retailer and Stackelberg-manufacturer games; Huang et al. (2011) study coordinating pricing, inventory decisions, and supplier selection in a supply chain; Sarlak and Nookabadi (2012) study a three-level supply chain to synchronize the timing of retailers' orders with the supplier's order cycle by timing discount contract; Pezeshki et al. (2012) consider a type of revenue sharing reservation contract with penalty in a supply chain for coordinating price and capacity building decisions; Kunter (2012) applies cost and revenue sharing mechanism to coordinate the channel.

\section{Model Formulation}

\subsection{Notation}

In this paper, we use a notation for representing the parameters and the decision variables to model the inventory management problem in a two-echelon supply chain. 


\section{Parameters:}

A Retailer fixed ordering cost

$A^{\prime} \quad$ Manufacturer fixed setup cost

$h \quad$ Retailer unit holding cost per unit time

$H \quad$ Manufacturer unit holding cost per unit time

I The accumulated inventory in a cycle

$T \quad$ Cycle time

$D \quad$ Price-dependent annual market demand

$p \quad$ Retail price $p e r$ unit (decision variable), $\mathrm{p}>0$

$w \quad$ Wholesale price per unit (decision variable), $\mathrm{c}<\mathrm{w}<\mathrm{p}$

$c \quad$ Procurement cost per unit, $0<\mathrm{c}<\mathrm{W}$

k1 Time-dependent production cost per unit time

k2 Technology development cost, per one unit increasing on the production rate

$l \quad$ Lead time

$\mu \quad$ Manufacturer production rate

$Q \quad$ Order quantity (decision variable)

$\prod_{R} \quad$ Retailer's profit

$\prod_{M}$ Manufacturer's profit

$\prod_{I} \quad$ Integrated supply chain (centralized) profit

$\prod_{T} \quad$ Total supply chain profit (sum of the retailer's and manufacturer's profit)

Suppose th the total market demand is price-dependent with $D_{p}=a-b p$ in which $a$ and $b$ are positive and $p \in(c, a / b)$. The parameter $b$ is the demand elasticity with respect to retail price. We consider three policies: centralized or integrated, decentralized with Stackelberg game, and decentralized with retail fixed mark up (RFM) policy.

\subsection{Retailer's Objective Function}

The retailer uses the EOQ inventory policy for controlling his costs. We assume that the demand is deterministic but changing with retail price. The retailer's objective function includes the profit of the products, average holding cost and, average ordering cost, and therefore, the objective function of the retailer is given by:

$$
\Pi_{R}=(p-w) D_{p}-\frac{A D_{p}}{Q}-\frac{Q}{2}=\left(p-w-\frac{A}{Q}\right)(a-b p)-\frac{h Q}{2}
$$

\subsection{Manufacture's Objective Function}

The manufacturer places order from an outside supplier with zero lead time. We consider a cost function for the manufacturer that consists of the holding cost, the setup costs, and time-dependent production cost. Holding cost is incurred only for 
finished products. We also split the setup costs into two parts: one part is fixed for every production period, and another one is an increasing function of the production rate. For example, assume an assembly line that has the technology for assembling a set of parts that are supplied by a supplier. In this assembly line, time-dependent production cost coincides with the daily production cost. If the production rate exceeds a specific limit, it is necessary to enhance the technology. For simplifying the problem, we assume that for every increasing unit on the production rate, the manufacturer incurred a cost called technology development cost. For instance, if the manufacturer incurred $\$ 200$ for increasing 100 units on the production rate, then the unit technology development cost will be $\$ 2$. Figure 1 shows the manufacturer's inventory level.

Figure 1

\section{Manufacturer's Inventory Level}

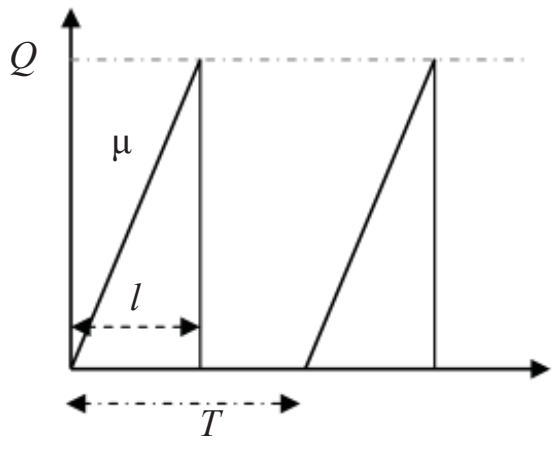

In this particular setting, the manufacturer's production cycle is equal to the retailer's replenishment cycle. The manufacturer operates on a make-to-order basis using a lotfor-lot policy, therefore, the manufacturer begins to produce a batch of $Q$ at the rate of $\mu$, as soon as he receives an order and delivers it to the retailer after the lead time. We assume that the manufacturer has to produce the product with minimum possible production rate during the lead time, so $\mu$ is equal to $Q / l$.

Knowing that $Q / T=D_{p}=a-b p$, the objective functions for the manufacturer would be:

$$
\Pi_{M}=\frac{(w-c) Q-\left[A^{\prime}+H Q l / 2+k_{1} Q / \mu+k_{2} \mu\right.}{T}=(a-b p)\left[w-c-\frac{A}{Q}-\frac{H l}{2}-\frac{k_{1} l}{Q}-\frac{k_{2}}{l}\right]
$$

where HQ1/2 denotes the inventory holding cost during a production period. Note that in every cycle, production lasts $\mathbf{Q} / \boldsymbol{\mu}$ time units, so, the time dependent production cost will be $\mathbf{k}_{1} \mathbf{Q} \boldsymbol{\mu}$. In addition, $\mathbf{k}_{2} \boldsymbol{\mu}$ is associated to the technology development costs. 


\section{Policies}

\subsection{Integrated policy}

In this policy, the goal is maximizing the sum of manufacturer's and retailer's profits. So the objective function of the whole supply chain is achieved from equations (1) and (2) as below:

$$
\Pi_{\mathrm{I}}=(a-b p)\left[p-c-\frac{\left(A^{\prime}+A+k_{1} l\right)}{Q}-\frac{H l}{2}-\frac{k_{2}}{l}\right]-\frac{h \cdot Q}{2}
$$

Where decision variables are: retail price $(p)$ and order quantity $(Q)$.

Proposition 1: The integrated order quantity is one of the positive roots of the following equation:

$$
Q^{3}-\left[a-b\left(c+\frac{H l}{2}+\frac{k_{2}}{l}\right)\right] \frac{\left(A^{\prime}+A+k_{1} l\right)}{h} Q+\frac{b\left(A^{\prime}+A+k_{1} l\right)^{2}}{h}=0
$$

And, integrated retail price is:

$$
p^{*}=\frac{1}{2}\left[\frac{a}{b}+c+\frac{A^{\prime}+A+k_{1} l}{Q^{*}}+\frac{H l}{2}+\frac{k_{2}}{l}\right]
$$

Proof: The optimal retail price, $p^{*}$, is achieved from $\partial \Pi_{I} / \partial p=0$. Similarly, the optimal order quantity is $Q^{*}=\sqrt{2(a-b p)\left(A^{\prime}+A+k_{1} l\right)} / \sqrt{h}$, and, the Equation can be easily obtained by simultaneously considering $p^{*}$, and $Q^{*}$. It can be proved that this form of equations either has two positive roots or have no one. Note that the Hessian matrix is a negative definite matrix, so, $\Pi_{\mathrm{I}}$ is a concave function in $p$ and $Q$. Therefore, $\left(p^{*}, Q^{*}\right)$ maximizes the integrated profit function.

$$
H=\left[\begin{array}{cc}
\frac{\partial^{2}}{\partial p^{2}} & \frac{\partial^{2}}{\partial p \partial Q} \\
\frac{\partial_{\mathrm{I}}^{2}}{\partial Q \partial \vec{p}} & \frac{\partial_{\mathrm{I}}^{2}}{\partial Q^{2}}
\end{array}\right]=\left[\begin{array}{cc}
-2 b & -b Q^{-2}\left(A^{\prime}+A+k_{1} l\right) \\
-b Q^{-2}\left(A^{\prime}+A+k_{1} l\right) & -2 Q^{-3}\left(A^{\prime}+A+k_{1} l\right)(a-b p)
\end{array}\right]
$$

\subsection{Decentralized (Stackelberg policy)}

In a Stackelberg approach, players are classified as leader and follower. The leader chooses a strategy first, and then the follower observes this decision and makes his own strategy. It is necessary to assume that each enterprise is not willing to deviate from maximizing his profit. In other words, each player chooses his best strategy. Here, the manufacturer is the leader, and the retailer is the follower. The manufacturer 
determines his wholesale price, and acts as a leader by announcing it to the retailer in advance, and the retailer acts as a follower by choosing his retail price and order quantity based on the manufacturer's strategy. We will use term "Stag" for Stackelberg policy.

Proposition 2: The Stag's order quantity and wholesale price are obtained by solving the following system of equations:

$$
\begin{gathered}
(I): \frac{h}{A} Q^{2}-(a-b w)+\frac{b A}{Q}=0, \quad \text { and } \\
\begin{array}{c}
(I I): w\left[-2 Q^{4}+\left(A-\frac{2 h Q^{3}}{b A}\right)\left(A-A^{\prime}-k_{1} l\right)\right]-\left(A^{2}-\frac{2 h Q^{3}}{b}-Q^{4}\right)\left(c+\frac{A^{\prime}+k_{1} l}{Q}+\frac{H l}{2}+\frac{k_{2}}{l}\right)- \\
-\left[Q^{4}+\left(A-\frac{2 h Q^{3}}{b A}\right)\left(A^{\prime}+k_{1} l\right)\right]\left(-\frac{a}{b}+\frac{A}{Q}\right)=0
\end{array}
\end{gathered}
$$

and, Stag's retail price is:

$$
p^{*}=\frac{1}{2}\left[w+\frac{a}{b}+\frac{A}{Q}\right]
$$

Proof: We need the retailer's reaction function $\left(p^{*}, Q^{*}\right)$ for given $w . \Pi_{\mathrm{R}}$ is concave in $p$ and $Q$, since the Hessian matrix is a negative definite matrix. It can be proved in the same way as we proved in Proposition 1. So, the optimal retail price and the optimal order quantity are achieved from $\partial \Pi_{\mathrm{R}} / \partial p=\partial \Pi_{\mathrm{R}} / \partial Q=0$.

$$
\begin{gathered}
p=\frac{w}{2}+\frac{a}{2 b}+\frac{A}{2 Q} \\
Q=\sqrt{\frac{2(a-b p) A}{h}}
\end{gathered}
$$

By simultaneously considering equations (5) and (6), we get Equation (I). Now, substitute $p$ in the manufacturer's objective function:

$$
\Pi_{\mathrm{M}}=\left[a-b\left(\frac{w}{2}+\frac{a}{2 b}+\frac{A}{2 Q}\right)\right]\left[w-c-\frac{A^{\prime}}{Q}-\frac{H l}{2}-\frac{k_{1} l}{Q}-\frac{k_{2}}{l}\right]
$$

The optimal wholesale price is achieved by maximizing equations (7) with respect to $w$ or equivalently $\partial \Pi_{\mathrm{M}} / \partial w=0$ :

$$
\frac{\partial \Pi_{\mathrm{M}}}{\partial w}=\left(-\frac{b}{2}+\frac{b A}{2 Q^{2}} \frac{\partial Q}{\partial w}\right)\left(w-c-\frac{A^{\prime}}{Q}-\frac{H l}{2}-\frac{k_{1} l}{Q}-\frac{k_{2}}{l}\right)+\left(1+\frac{A^{\prime}+k_{1} l}{Q^{2}} \frac{\partial Q}{\partial w}\right)\left(\frac{a}{2}-\frac{b w}{2}-\frac{b A}{2 Q}\right)
$$



Where $\partial Q / \partial w$ calculated from equation (I) and is equal to $\frac{A}{Q^{2}}-\frac{2 h Q}{b A}$. Simplifying
Equation (8) results the Equation (II).

\subsection{Decentralized (RFM policy)}

In this policy, the manufacturer sets his wholesale price first. Next the retailer chooses his order quantity. The retailer receives a fixed mark-up $(\alpha=1-w / p)$. So, choosing the wholesale price by manufacturer is equivalent to setting the retail price. Then, the retailer only decides on value of order quantity and the manufacturer chooses the retail price. Note that, the value of $\alpha$ is assumed to be exogenously given, and, not to be endogenously determined. It is important to specify that for which values of $\alpha$, the RFM policy will be desirable for both members. By substituting $\mathrm{w}=(1-\alpha) p$ to EQ (1) and EQ (2), we get the objective functions of two firms under RFM as below:

$$
\begin{gathered}
\Pi_{\mathrm{R}}=\left(\alpha p-\frac{A}{Q}\right)(a-b p)-\frac{h Q}{2} \\
\Pi_{\mathrm{M}}=(a-b p)\left[(1-\alpha) p-c-\frac{A^{\prime}+k_{1} l}{Q}-\frac{H l}{2}-\frac{k_{2}}{l}\right]
\end{gathered}
$$

Proposition 3: RFM's order quantity and retail price are obtained by solving the following system of equations:

(I): $\frac{h}{2 A} Q^{2}-(a-b p)=0$, and

$(I I):-p\left(2-2 \alpha-\frac{h}{b A} \frac{A^{\prime}+k_{1} l}{Q}\right)+c+\frac{A^{\prime}+k_{1} l}{Q}+\frac{H l}{2}+\frac{k_{2}}{l}+\frac{a}{b}\left(1-\alpha-\frac{h}{b A} \frac{A^{\prime}+k_{1} l}{Q}\right)=0$

Proof: Similar to previous section, the retailer' reaction, $Q$, is achieved as the same as EQ (6) from $\partial \Pi_{\mathrm{R}} / \partial Q=0$. Here, the manufacturer maximizes his objective function by taking the retailer's reaction into account. Differentiating EQ (10) with respect to $p$, we get:

$$
\frac{\partial \Pi_{\mathrm{M}}}{\partial p}=-b\left[(1-\alpha) p-c-\frac{A^{\prime}+k_{1} l}{Q}-\frac{H l}{2}-\frac{k_{2}}{l}\right]+(a-b p)\left(1-\alpha+\frac{A^{\prime}+k_{1} l}{Q^{2}} \frac{\partial Q}{\partial p}\right)=0
$$

Where $\partial Q / \partial p$ calculated from Equation (I) is equal to $h Q / b A$. Simplifying the above equation results the Equation (II). Also, concavity of the profit functions can be proved similar to the previous sections. 


\section{Numerical Study}

A numerical study is provided to quantify our analytical results and concepts from the previous sections to gain some managerial insights. We present a base case to compare the results of different policies. We proceed to illustrate the Pareto-improvement region through a numerical study. Finally, we perform a sensitivity analysis of two firms' decision by changing the values of major parameters. We applied MAPLE 12 for evaluating the problem.

\subsection{Base case}

In our numerical study, we consider a base-case values, which are presented in Table 1.

Table 1

Parameter Values of the Base-Case

\begin{tabular}{|l|c|c|c|c|c|c|c|c|c|c|}
\hline Parameter & $\boldsymbol{A}$ & $\boldsymbol{A}^{\prime}$ & $\boldsymbol{h}$ & $\boldsymbol{H}$ & $\boldsymbol{A}$ & $\boldsymbol{b}$ & $\boldsymbol{k 1}$ & $\boldsymbol{k 2}$ & $\boldsymbol{c}$ & $\boldsymbol{L}$ \\
\hline Value & 80 & 300 & 1.2 & 1 & 56000 & 2000 & 1000 & .0002 & 13 & .02 \\
\hline
\end{tabular}

Table 2 summarizes the solutions of three policies for the base-case values. In RFM policy it is assumed that $\alpha$ is equal to 0.1. As shown in the table, the retailer's and manufacturer's profit is higher in RFM policy comparing to Stag policy. Note that the competition penalty $(\rho)$ is the difference between the integrated profit and Stag/ RFM profit measured as a fraction of the integrated profit. For Stag policy, this value is equal to $27 \%$ but decreased to $2 \%$ in RFM policy. We will show that for an interval $\left(\alpha_{\min }, \alpha_{\max }\right)$ both the manufacturer and retailer can benefit from RFM policy.

Table 2

Solutions of Two Approaches for the Base-Case Example

\begin{tabular}{|l|r|r|r|r|r|r|}
\hline & \multicolumn{1}{|c|}{$\mathbf{Q}^{*}$} & $\boldsymbol{W}^{*}$ & $\boldsymbol{p}^{*}$ & $\Pi_{R}$ & $\Pi_{M}$ & $\Pi_{T}$ \\
\hline Integrated Policy & 3146.7 & - & 20.6 & - & - & 108416 \\
\hline Stag Policy & 986 & 20.6 & 24.4 & 25960 & 53102 & 79062 \\
\hline RFM(0.1) Policy & 1330 & 19.2 & 21.4 & 26750 & 79194 & 105943 \\
\hline
\end{tabular}

Figure 2 illustrates the retailer's and manufacturer's profit functions with respect to $\alpha$ under the RFM and Stackelberg policies. As shown in the figure, the thick-lined regions in both curves demonstrate the regions in which RFM policy is preferred to Stag policy. There exists a maximum value for $\alpha$ (i.e. $\ddot{\alpha})$ to assure non-negative profit for the both manufacturer and retailer. For base case data, there are not feasible strategy for the manufacturer and retailer if $\alpha$ is greater than 0.48 . In other words for $\ddot{\alpha} \geq 0.48$, the total profit of RFM policy will be lower than that of Stag policy and, 
also, the manufacturer's profit will be negative. So, if members of supply chain can coordinate to use RFM policy, in the feasible range of $\alpha$, at least, one member can benefit the advantage of this policy.

Figure 2

\section{Variations of Profit Functions Respect to a}

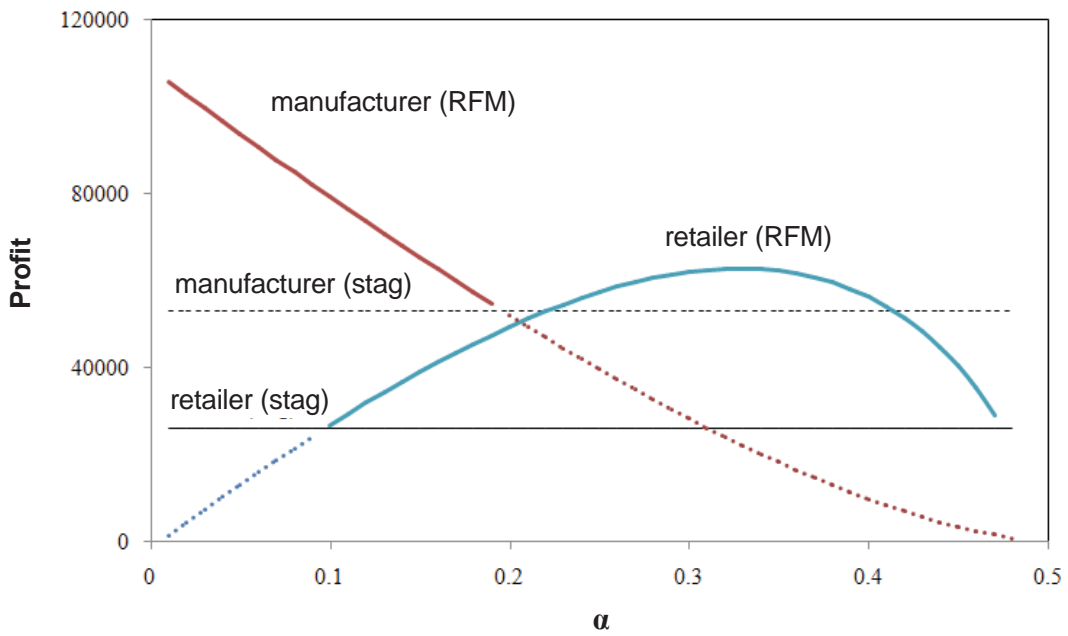

The manufacturer's profit function is convex and decreasing in $\alpha$, however, the retailer's one is concave and has a maximum value (see Figure 2). There exists a $\alpha_{\max }$ such that if $\alpha \leq \alpha_{\max }=0.19$, the manufacturer will always prefer RFM policy to Stag policy. Similarly, there exists a $\alpha_{\min }$ such that if $\alpha \geq \alpha_{\min }=0.1$, the retailer will always prefer RFM policy to Stag policy.

Observation 1: The interval $\left(\alpha_{\min ,} \alpha_{\max }\right)$ is a Pareto efficient strategy.

There exists an interval $\left(\alpha_{\min ,} \alpha_{\max }\right)$ in which both the retailer and manufacturer can benefit from RFM policy comparing to Stag policy. This interval is $(0.1,0.19)$ for base case data. We investigate this Pareto-improving region numerically. Figures 3 and 4 illustrate the variations of this region with respect to $\mathrm{A}$ and $\mathrm{b}$, respectively. 


\section{Figure 3}

Pareto-Improving Region in A

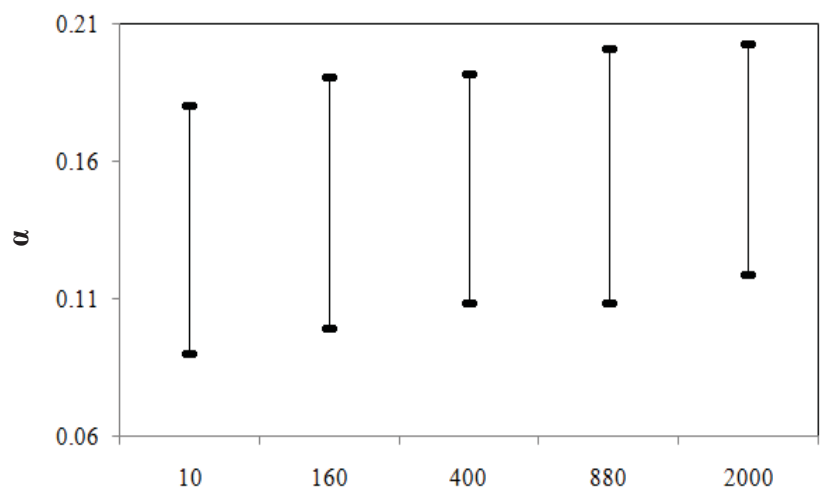

A

Figure 4

Pareto-Improving Region in b

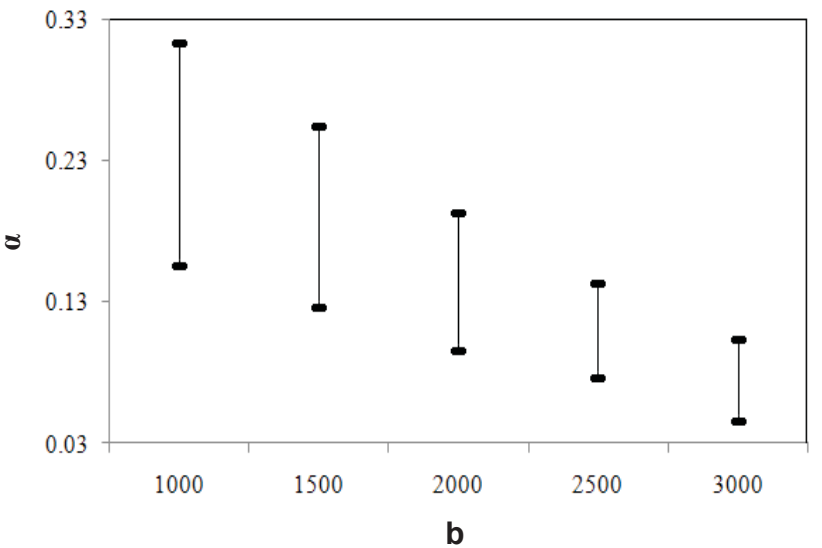

\subsection{Sensitivity Analysis}

In this subsection, we perform a sensitivity analysis by changing the values of major parameters in the base-case. We define $\Delta m$ as the manufacturer's percentage improvement of RFM policy comparing to Stag policy. Similarly we define $\Delta r$ for the retailer's. Table 3 shows the sensitivity analysis of these values and the competition penalty $(\rho)$ for RFM policy with three different retail fixed mark-up rates. Negative values show that the manufacturer's/retailer's profit in Stag policy is higher than that of RFM's. Consider that where either $\Delta m$ or $\Delta r$ is negative, the RFM is not a Pareto efficient strategy. 
Table 3

Two Approach Solutions under Variation of Base-Case Parameters

\begin{tabular}{|c|c|c|c|c|c|c|c|c|c|c|c|}
\hline \multirow{2}{*}{\multicolumn{2}{|c|}{$\begin{array}{l}\text { Solutions } \rightarrow \\
\text { Parameters } \downarrow\end{array}$}} & \multirow{3}{*}{$\begin{array}{c}\text { Stag } \\
\rho \\
26\end{array}$} & \multicolumn{3}{|c|}{ RFM(0.1) } & \multicolumn{3}{|c|}{ RFM(0.2) } & \multicolumn{3}{|c|}{ RFM(0.3) } \\
\hline & & & \multirow{2}{*}{$\frac{\rho}{1}$} & \multirow{2}{*}{$\begin{array}{l}\Delta_{m} \\
69\end{array}$} & \multirow{2}{*}{$\begin{array}{r}\Delta_{r} \\
-35\end{array}$} & \multirow{2}{*}{$\frac{\rho}{2}$} & \multirow{2}{*}{$\begin{array}{l}\Delta_{m} \\
35\end{array}$} & \multirow{2}{*}{$\begin{array}{l}\Delta_{r} \\
30\end{array}$} & \multirow{2}{*}{$\frac{\rho}{3}$} & \multirow{2}{*}{$\begin{array}{r}\Delta_{m} \\
3\end{array}$} & \multirow{2}{*}{$\begin{array}{c}\Delta_{r} \\
90\end{array}$} \\
\hline$C$ & 7 & & & & & & & & & & \\
\hline & 18 & 29 & 7 & 17 & 60 & 26 & -56 & 127 & 82 & -98 & -26 \\
\hline \multirow[t]{2}{*}{$B$} & 1200 & 26 & 1 & 66 & -31 & 1 & 31 & 36 & 3 & -3 & 96 \\
\hline & 2600 & 29 & 6 & 27 & 46 & 20 & -42 & 129 & 57 & -90 & 68 \\
\hline \multirow[t]{2}{*}{$A$} & 45000 & 29 & 5 & 32 & 37 & 17 & -34 & 125 & 45 & -82 & 101 \\
\hline & 75000 & 26 & 1 & 61 & -20 & 2 & 21 & 54 & 6 & -17 & 115 \\
\hline \multirow[t]{2}{*}{$A$} & 40 & 28 & 3 & 49 & 5 & 8 & -3 & 92 & 18 & -48 & 139 \\
\hline & 200 & 26 & 1 & 50 & 0 & 5 & -1 & 89 & 15 & -46 & 140 \\
\hline \multirow[t]{2}{*}{$A^{\prime}$} & 150 & 26 & 1 & 49 & 2 & 5 & -2 & 88 & 15 & -46 & 138 \\
\hline & 600 & 29 & 4 & 50 & 6 & 9 & -3 & 95 & 20 & -49 & 140 \\
\hline \multirow[t]{2}{*}{$H$} & 1 & 27 & 2 & 49 & 3 & 6 & -2 & 90 & 16 & -47 & 139 \\
\hline & 3 & 28 & 3 & 51 & 3 & 8 & -2 & 93 & 19 & -48 & 142 \\
\hline \multirow[t]{2}{*}{$H$} & 0.5 & 27 & 2 & 49 & 3 & 7 & -2 & 90 & 17 & -47 & 139 \\
\hline & 1.2 & 27 & 2 & 49 & 3 & 7 & -2 & 90 & 17 & -47 & 139 \\
\hline \multirow[t]{2}{*}{ k1 } & 500 & 27 & 2 & 49 & 3 & 6 & -2 & 90 & 17 & -47 & 139 \\
\hline & 2000 & 27 & 2 & 49 & 3 & 7 & -2 & 90 & 17 & -47 & 139 \\
\hline \multirow[t]{2}{*}{$k 2$} & 0.0001 & 27 & 2 & 49 & 3 & 7 & -2 & 90 & 17 & -47 & 139 \\
\hline & 0.001 & 27 & 2 & 49 & 3 & 7 & -2 & 91 & 17 & -47 & 139 \\
\hline \multirow[t]{2}{*}{$L$} & 0.01 & 27 & 2 & 49 & 3 & 6 & -2 & 90 & 17 & -47 & 139 \\
\hline & 0.1 & 28 & 3 & 49 & 4 & 7 & -3 & 92 & 18 & -48 & 139 \\
\hline
\end{tabular}

Table 4 shows the variations of decision variables for integrated, Stag, and RFM with three different retail fixed mark-up rate.

We solve 1,000 problems and drive conclusions about the results. To evaluate the RFM policy, we set $\alpha$ to 0.14 , but other parameters generated randomly from the intervals as below:

$$
\begin{gathered}
c \in(7,18), a \in(45000,75000), b \in(1200,2600), A \in(40,200), A^{\prime} \in(150,600) \\
h \in(1,3), H \in(0.5,1.2), k_{1} \in(500,2000), k_{2} \in(0.0001,0.001), l \in(0.01,0.1)
\end{gathered}
$$

Solving the problems, in 590 problems, both firms prefer to utilize RFM (0.14) policy rather than Stag policy. In other words, $\alpha=0.14$ is in the Pareto-improving region of the 590 problems. Then, we compare the competition penalty for these problems. The average competition penalty is $28 \%$ in Stag policy, but decreased to less than $4 \%$ in RFM (0.14) policy. Moreover, the maximum penalty is $37 \%$ and $16 \%$ in Stag and RFM (0.14) policies, respectively. So, the average and minimum of RFM policy's efficiency is $96 \%$ and $84 \%$ respectively. Figures 5 and 6 illustrate the penalty's histogram for Stag and RFM policies. 
Table 4

Two Approach Solutions under Variation of Base-Case Parameters

\begin{tabular}{|c|c|c|c|c|c|c|c|c|c|c|c|c|c|c|c|}
\hline \multirow{2}{*}{\multicolumn{2}{|c|}{$\begin{array}{l}\text { Solutions } \rightarrow \\
\text { Parameters } \downarrow\end{array}$}} & \multicolumn{2}{|c|}{ Integrated } & \multicolumn{3}{|c|}{ Stag } & \multicolumn{3}{|c|}{$\operatorname{RFM}(0.1)$} & \multicolumn{3}{|c|}{$\operatorname{RFM}(0.2)$} & \multicolumn{3}{|c|}{$\operatorname{RFM}(0.3)$} \\
\hline & & $Q$ & $p$ & $\boldsymbol{Q}$ & $p$ & $w$ & $\boldsymbol{Q}$ & $p$ & $w$ & $\boldsymbol{Q}$ & $P$ & $w$ & $\boldsymbol{Q}$ & $p$ & $w$ \\
\hline & 7 & 3730 & 17.6 & 1174 & 22.8 & 17.6 & 1632 & 18 & 16.2 & 1591 & 18.5 & 14.8 & 1535 & 19.2 & 13.4 \\
\hline & 18 & 2559 & 23.1 & 796 & 25.6 & 23.2 & 1008 & 24.2 & 21.8 & 815 & 25.5 & 20.4 & 368 & 27.5 & 19.3 \\
\hline \multirow{2}{*}{$b$} & 200 & 3663 & 29.9 & 1154 & 38.3 & 29.9 & 1599 & 30.7 & 27.6 & 1553 & 31.6 & 25.3 & 1490 & 32.8 & 23 \\
\hline & 2600 & 2693 & 17.4 & 836 & 19.5 & 17.4 & 1081 & 18.2 & 16.4 & 915 & 19.1 & 15.3 & 617 & 20.4 & 14.3 \\
\hline \multirow{2}{*}{ a } & 5000 & 2493 & 17.8 & 774 & 20.3 & 17.9 & 1012 & 18.7 & 16.8 & 877 & 19.6 & 15.7 & 653 & 20.9 & 14.6 \\
\hline & 75000 & 4032 & 25.3 & 1270 & 31.5 & 25.4 & 1745 & 26.1 & 23.5 & 1673 & 27 & 21.6 & 1575 & 28.2 & 19.7 \\
\hline \multirow{2}{*}{ A } & 40 & 2986 & 20.6 & 695 & 24.4 & 20.7 & 936 & 21.4 & 19.3 & 867 & 22.4 & 17.9 & 766 & 23.6 & 16.5 \\
\hline & 200 & 3586 & 20.6 & 1564 & 24.3 & 20.5 & 2111 & 21.3 & 19.2 & 1960 & 22.2 & 17.8 & 1745 & 23.4 & 16.4 \\
\hline \multirow{2}{*}{$A^{\prime}$} & 150 & 2490 & 20.6 & 992 & 24.3 & 20.6 & 1336 & 21.3 & 19.2 & 1241 & 22.2 & 17.8 & 1106 & 23.4 & 16.4 \\
\hline & 600 & 4157 & 20.6 & 976 & 24.4 & 20.8 & 1317 & 21.5 & 19.3 & 1216 & 22.5 & 18 & 1069 & 23.7 & 16.6 \\
\hline \multirow{2}{*}{$h$} & 1 & 3448 & 20.6 & 1082 & 24.3 & 20.6 & 1458 & 21.4 & 19.3 & 1352 & 22.3 & 17.8 & 1201 & 23.5 & 16.5 \\
\hline & 3 & 1985 & 20.6 & 619 & 24.4 & 20.7 & 836 & 21.4 & 19.3 & 773 & 22.4 & 17.9 & 682 & 23.6 & 16.5 \\
\hline \multirow{2}{*}{$H$} & 0.5 & 3147 & 20.6 & 987 & 24.4 & 20.6 & 1330 & 21.4 & 19.3 & 1233 & 22.3 & 17.8 & 1095 & 23.5 & 16.5 \\
\hline & 1.2 & 3147 & 20.6 & 986 & 24.4 & 20.6 & 1330 & 21.4 & 19.3 & 1233 & 22.3 & 17.8 & 1094 & 23.5 & 16.5 \\
\hline \multirow{2}{*}{$k 1$} & 500 & 3107 & 20.6 & 987 & 24.4 & 20.6 & 1330 & 21.4 & 19.3 & 1233 & 22.3 & 17.8 & 1095 & 23.5 & 16.5 \\
\hline & 2000 & 3224 & 20.6 & 986 & 24.4 & 20.6 & 1329 & 21.4 & 19.3 & 1232 & 22.3 & 17.8 & 1093 & 23.5 & 16.5 \\
\hline \multirow{2}{*}{$k 2$} & 0.0001 & 3147 & 20.6 & 986 & 24.4 & 20.6 & 1330 & 21.4 & 19.3 & 1233 & 22.3 & 17.8 & 1095 & 23.5 & 16.5 \\
\hline & 0.001 & 3142 & 20.6 & 988 & 24.4 & 20.7 & 1328 & 21.4 & 19.3 & 1230 & 22.3 & 17.8 & 1091 & 23.5 & 16.5 \\
\hline & 0.01 & 3107 & 20.6 & 987 & 24.4 & 20.6 & 1330 & 21.4 & 19.3 & 1233 & 22.3 & 17.8 & 1095 & 23.5 & 16.5 \\
\hline & 0.1 & 3442 & 20.6 & 982 & 24.4 & 20.7 & 1325 & 21.4 & 19.3 & 1226 & 22.4 & 17.9 & 1085 & 23.6 & 16.5 \\
\hline
\end{tabular}

Figure 5

Histogram of Stag Policy' Penalty

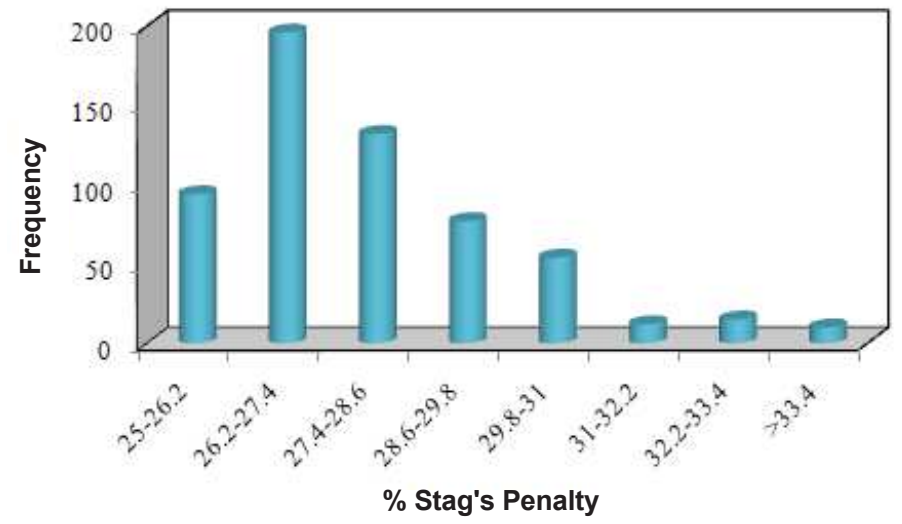

PRAGUE ECONOMIC PAPERS, 2, 2014 
Figure 6

\section{Histogram of RFM Policy' Penalty}

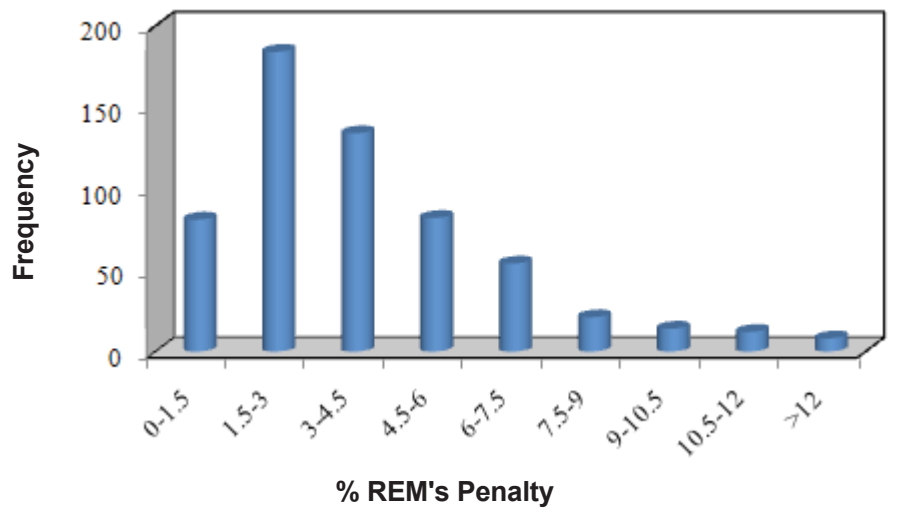

Figure 7 illustrates the variations of total profit respect to the retailer's fixed ordering cost. It is obvious that total profit of the RFM is higher than that of Stag policy. Figure 8 shows the variations of retail price respect to the procurement cost. We examine four different values of $\alpha$. The retail price is increasing in $c$. As shown in the figure, we can only say that the retail price of Stag policy is greater than that of integrated policy. Figure 9 illustrates the variations of order quantity respect to the procurement cost. The order quantity is decreasing in $c$. Generally, the order quantity of integrated policy is greater than those of RFM and Stag policies. As $\alpha$ increases, there will not be a feasible solution of RFM policy for greater values of the procurement cost.

Figure 7

\section{Total Profit Respect to A}

$\multimap$ Integrated $\rightarrow-$ Stag $\multimap \operatorname{RFM}(.15) \rightarrow \operatorname{RFM}(.2)$

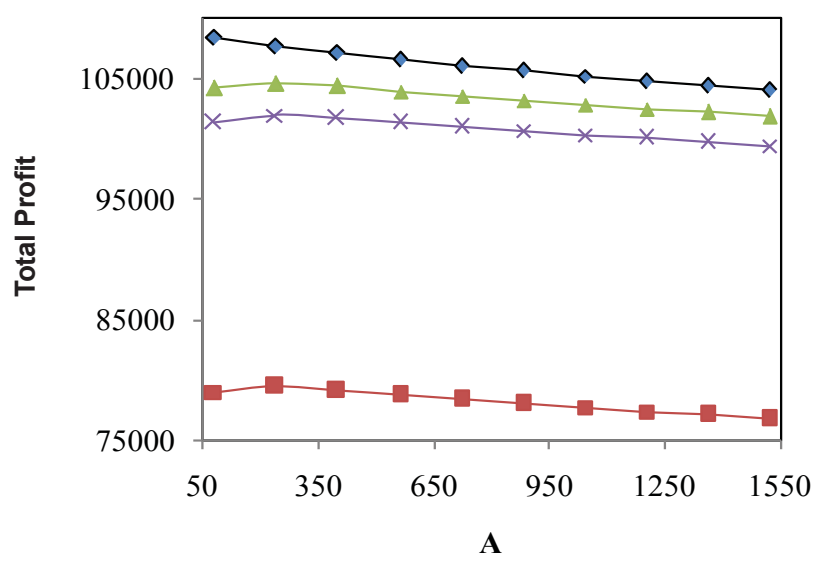




\section{Figure 8}

\section{Retail Price Respect to c}

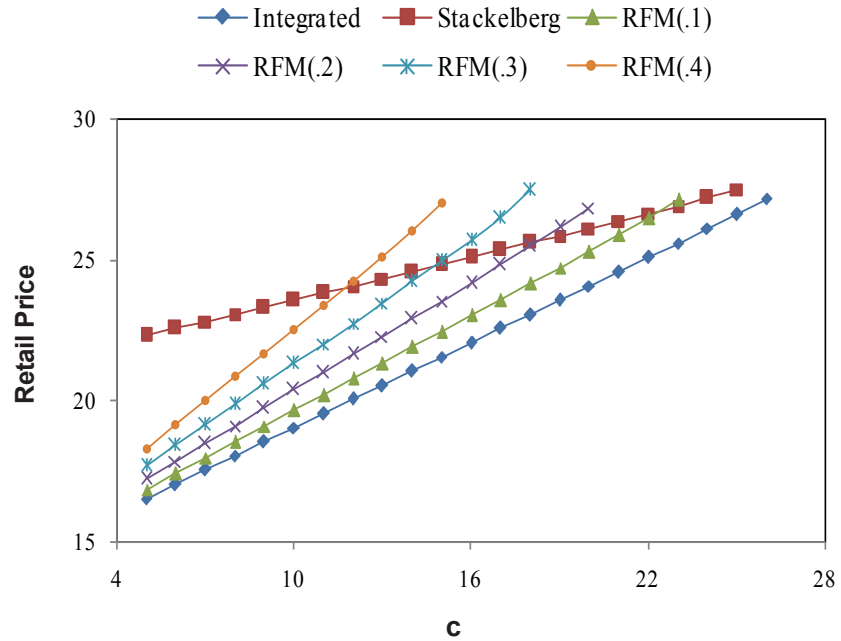

Figure 9

Order Quantity Respect to c

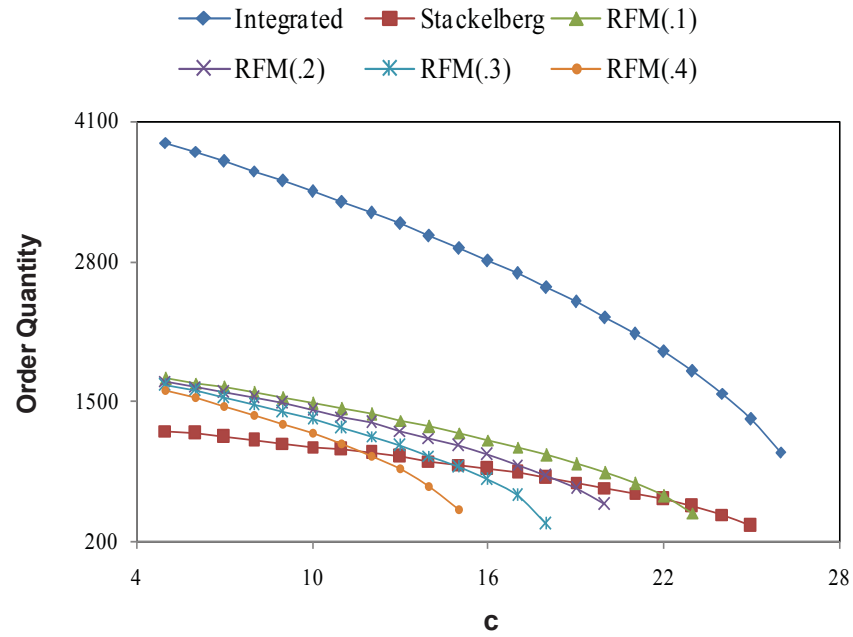

Figures 10 and 11 illustrate the variations of retailer's and manufacturer's profit, respectively. It is shown that greater value of $\alpha$ leads to greater profit for the retailer, but lower profit for the manufacturer. It is obvious that RFM with $\alpha=0.1$ is preferred by the retailer only for $\mathrm{A}<240$. And, RFM with $\alpha=0.1$ is desirable for the manufacturer with A $>400$. This observation approves the results achieved by Figure 3 . 
Figure 10

Retailer's Profit Respect to A

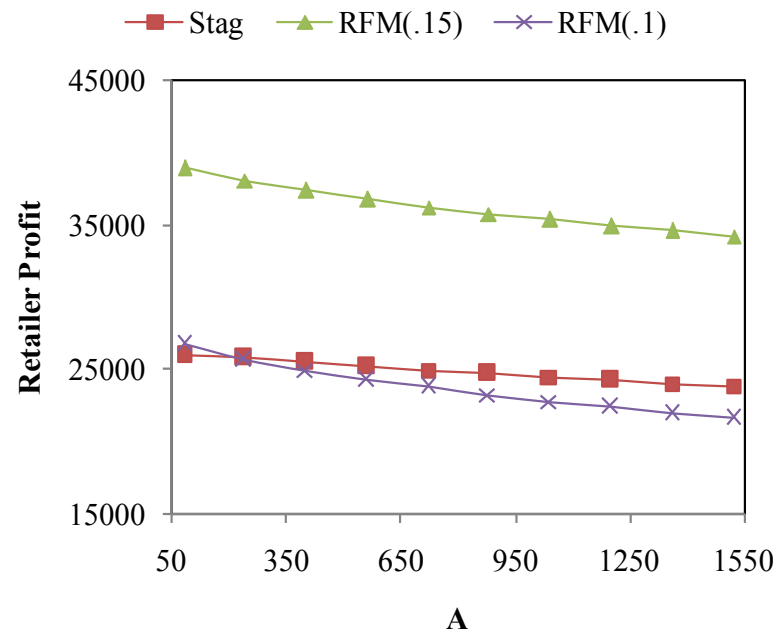

Figure 11

Manufacturer's Profit Respect to A

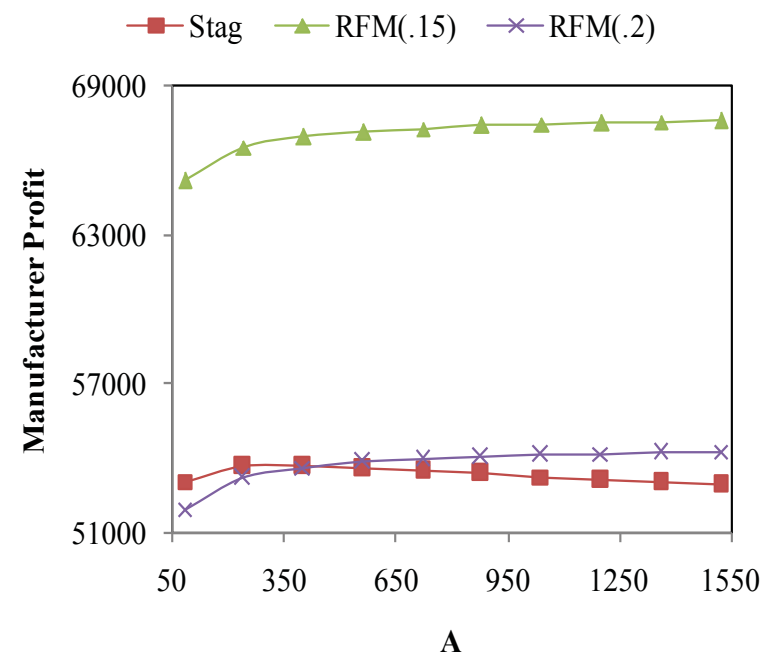

\section{Conclusions and Discussion}

A production inventory problem is considered in a two-level supply chain, and, a specific policy (i.e. RFM) is examined with the aim of coordinating the channel. There are many types of contract in the literature that guarantee coordinating the supply chain, but, their administrative costs are neglected in practice. The additional gain 
from coordination may not necessarily cover the extra administrative costs imposed to supply chain. For this reason, we use RFM policy because of its minor administrative costs comparing to the other policies.

We found that without RFM policy (i.e. Stag policy), the average and minimum efficiency is about $72 \%$ and $63 \%$, respectively. But, with a properly designed RFM, Pareto improvement is achieved over the Stag policy. By setting appropriate $\alpha$ in RFM policy, the average and minimum efficiency will be increased to $96 \%$ and $84 \%$, respectively. So, this policy is not capable of coordinating the channel; however, it leads to considerable improvements over the channel.

Our research could be extended by applying RFM policy for more general demand function with more efficient inventory models. Also, it will be interesting if the administrative costs of the coordination contracts are considered in the objective function of the members.

\section{References}

Arcelus, F. J., Srinivasan, G. (1987), "Inventory Policies under Various Optimizing Criteria and Variable Markup Rates." Management Science, Vol. 33, No. 6, pp.756-762.

Cachon, G. P., Lariviere, M. A. (2005), "Supply Chain Coordination with Revenue-Sharing Contracts: Strengths and Limitations." Management Science, Vol. 51, No. 1, pp. 30-44.

Cachon, G. P., Zipkin, P. H. (1999), "Competitive and Cooperative Inventory Policies in a Two-Stage Supply Chain." Management Science, Vol. 45, No. 7, pp. 936-953.

Chu, H., Wang, J., Jin, Y., Suo, H. (2006), "Decentralized Inventory Control in a Two-Component Assembly System." International Journal Production Economics, Vol. 102, No. 2, pp. 255-264.

Eliashberg, J., Steinberg, R. (1987), "Marketing-Production Decisions in an Industrial Channel of Distribution." Management Science, Vol. 33, No. 8, pp. 981-1000.

Ertek, G., Griffin, P. M. (2002), "Supplier- and Buyer-driven Channels in a Two-stage Supply Chain." IIE Transactions, Vol. 34, No. 8, pp. 691-700.

Ha, A. Y. (2001), "Supplier-Buyer Contracting: Asymmetric Cost Information and Cutoff Level Policy for Buyer Participation." Naval Research Logistics, Vol. 48, No. 1, pp. 41-64.

He, X., Prasad, A., Sethi, S. (2009), "Cooperative Advertising and Pricing in a Dynamic Stochastic Supply Chain: Feedback Stackelberg strategies." Production and Operations Management, Vol. 18, No. 1, pp. 78-94.

Huang, Y., Huang, G. Q., Newman, S. T. (2011), "Coordinating Pricing and Inventory Decisions in a Multi-Level Supply Chain: A Game Theoretic Approach." Transportation Research Part E: Logistics and Transportation Review, Vol. 47, No. 2, pp. 115-129.

Kadiyali, V., Naufel, V., Pradeep, C. (1998), "Product Line Extension and Competitive Market Interactions: An Empirical Analysis." Journal of Econometrics, Vol. 89, No. 1-2, pp. 339-363.

Karray, S., Martin-Herran, G. (2009), "A Dynamic Model for Advertising and Pricing Competition between National and Store Brands." European Journal of Operational Research, Vol. 193, No. 2, pp. 451-467.

Kunter, M. (2012), "Coordination via Cost and Revenue Sharing in Manufacturer-retailer Channels." European Journal of Operational Research, Vol. 216, No. 2, pp. 477-486.

Lau, A. H. L., Lau, H. S. (2004), „Some Two-echelon Supply-chain Games: Improving from Deterministic-Symmetric-Information to Stochastic-Asymmetric Information Models." European Journal of Operational Research, Vol. 161, No. 1, pp. 203-223. 
Lau, A. H. L., Lau, H. S. (2005), "A Critical Comparison of the Various Plausible Inter-Echelon Gaming Processes in Supply Chain Models." Journal of the Operational Research Society, Vol. 56, No. 11, pp. 1273-1286.

Li, Q., Atkins, D. (2002), "Coordinating Replenishment and Pricing in a Firm." Manufacturing \& Service Operations Management, Vol. 4, No. 4, pp. 241-257.

Li, S. X., Huang, Z. M., Ashley, A. (1995), "Seller-Buyer System Co-operation in a Monopolistic Market." Journal of The Operational Research Society, Vol. 46, No. 12, pp. 1456-1470.

Liou, Y. C., Schaible, S., Yao, J. C. (2006), "Supply Chain Inventory Management via a Stackelberg Equilibrium." Journal of Industrial and Management Optimization, Vol. 2, No. 1, pp. 81-94.

Liu, Y., Fry, M. J., Raturi, A. S. (2006), "Vertically Restrictive Pricing in Supply Chains with PriceDependent Demand." Naval Research Logistics, Vol. 53, No. 6, pp. 485-501.

Parlar, M., Wang, Q. (1994), "Discounting Decisions in a Supplier-Buyer Relationship with a Linear Buyer's Demand." IIE Transactions, Vol. 26, No. 2, pp. 34-41.

Pezeshki, Y., Baboli, A., Akbari, Jokar, M. R. (2012), "Simultaneous Coordination of Capacity Building and Price Decisions in a Decentralized Supply Chain." The International Journal of Advanced Manufacturing Technology, Vol. 64, No. 5-8, pp. 961-976.

Qin, Y., Tang, H., Guo, C. (2007), "Channel Coordination and Volume Discounts with Price-Sensitive Demand." International Journal of Production Economics, Vol. 105, No. 1, pp. 43-53.

Sarlak, R., Nookabadi, A. (2012), "Synchronization in Multi-Echelon Supply Chain Applying Timing Discount." The International Journal of Advanced Manufacturing Technology, Vol. 59, No. 1-4, pp. 289-297.

Seyed Esfahani, M. M., Biazaran, M., Gharakhani, M. (2011), "A Game Theoretic Approach to Coordinate Pricing and Vertical Co-op Advertising in Manufacturer-Retailer Supply Chains." European Journal of Operational Research, Vol. 211, No. 2, pp. 263-273.

Szmerekovsky, J., Zhang, J. (2009), "Pricing and Two-Tier Advertising with One Manufacturer and One Retailer." European Journal of Operational Research, Vol. 192, No. 3, pp. 904-917.

Viswanathan, S., Piplani, R. (2001), "Coordinating Supply Chain Inventories through Common Replenishment Epochs." European Journal of Operational Research, Vol. 129, No. 2, pp. 277-286.

Xie, J., Neyret, A. (2009), "Co-Op Advertising and Pricing Models in Manufacturer-Retailer Supply Chains." Computers \& Industrial Engineering, Vol. 56, No. 4, pp. 1375-1385.

Xie, J., Wei, J. C. (2009), "Coordinating Advertising and Pricing in a Manufacturer-Retailer Channel." European Journal of Operational Research, Vol. 197, No. 2, pp. 785-791.

Yang S. L., Zhou Y. W. (2006), "Two-Echelon Supply Chain Models: Considering Duopolistic Retailers' Different Competitive Behaviors." International Journal Production Economics, Vol. 103, No. 1, pp. 104-116.

Yue, J., Austin, J., Wang, M. C., Huang, Z. (2006), "Coordination of Cooperative Advertising in a Two-Level Supply Chain when Manufacturer Offers Discount." European Journal of Operational Research, Vol. 168, No. 1, pp. 65-85. 